Research Paper

\title{
An Anion-Induced Hydrothermal Oriented-Explosive Strategy for the Synthesis of Porous Upconversion Nanocrystals
}

\begin{abstract}
Peiyu Qiu, Rongjin Sun, Guo Gao ${ }^{\bowtie}$, Chunlei Zhang, Bin Chen, Naishun Yan, Ting Yin, Yanlei Liu, Jinging Zhang, Yao Yang, Daxiang Cui ${ }^{凶}$

Institute of Nano Biomedicine and Engineering, Department of Instrument Science and Technology, Key Laboratory for Thin Film and Microfabrication Technology of Ministry of Education, School of Electronic Information and Electrical Engineering, School of Mechanical Engineering, School of Materials Science and Engineering, Shanghai Jiao Tong University, Shanghai, 200240, China.
\end{abstract}

\author{
$\triangle$ Corresponding author: E-mail: guogao@sjtu.edu.cn (G. Gao), dxcui@sjtu.edu.cn (D. Cui) \\ (c) 2015 Ivyspring International Publisher. Reproduction is permitted for personal, noncommercial use, provided that the article is in whole, unmodified, and properly cited. \\ See http://ivyspring.com/terms for terms and conditions.
}

Received: 2014.10.29; Accepted: 2014.12.17; Published: 2015.02.06

\begin{abstract}
Rare-earth (RE)-doped upconversion nanocrystals (UCNCs) are deemed as the promising candidates of luminescent nanoprobe for biological imaging and labeling. A number of methods have been used for the fabrication of UCNCs, but their assembly into porous architectures with desired size, shape and crystallographic phase remains a long-term challenging task. Here we report a facile, anion-induced hydrothermal oriented-explosive method to simultaneously control size, shape and phase of porous UCNCs. Our results confirmed the anion-induced hydrothermal oriented-explosion porous structure, size and phase transition for the cubic/hexagonal phase of $\mathrm{NaLuF}_{4}$ and $\mathrm{NaGdF}_{4}$ nanocrystals with various sizes and shapes. This general method is very important not only for successfully preparing lanthanide doped porous UCNCs, but also for clarifying the formation process of porous UCNCs in the hydrothermal system. The synthesized UCNCs were used for in vitro and in vivo CT imaging, and could be acted as the potential CT contrast agents.
\end{abstract}

Key words: Hydrothermal; Anion-induced; Upconversion nanocrystals; Porous

\section{Introduction}

Compared to traditional bioprobes, such as quantum dots, organic fluorescent dyes or gold nanorods/clusters, rare-earth (RE)-doped upconversion nanocrystals (UCNCs) possess narrow absorption and emission bandwidths $(<10 \mathrm{~nm})$, long luminescence lifetime ( $\mu$ s to $m s$ range), low toxicity and deep tissue penetration with reduced photo-damage and auto-fluorescence. They have been used in biological imaging, [1-7] display devices, $[8,9]$ solar cells [10] and optical communication. [11] Because of their special $4 \mathrm{f}$ electron structure and unique optical-magnetic properties, lanthanide-based nanoprobes have attracted increasing attention in multimodal imaging as high-performance contrast agents. Applications in- clude X-ray computed tomography (CT), magnetic resonance imaging (MRI) and upconversion luminescence with potential applications for in vitro and in vivo imaging have been continuously developed. [12-16]

The common preparation techniques for upconversion nanocrystals include solvo-thermal methods, thermal decomposition, oil/ionic liquid two phase system and hydrothermal methods. Because of the simple and flexible operation, facile surface modification and functionalization via additives, environmentally friendly hydrothermal methods have been widely used in the preparation of nanocrystals, inorganic membranes and micro-porous materials. 
The synthesis of solid upconversion nanocrystal is effective,[17-29] such as the binary cooperative ligands with 6-aminohexanoic acid and oleate.[30-33] Some scientific research into the unique properties and synthesis of porous UCNCs have been reported. Thus far, there are three synthetic strategies for hollow UCNCs: (I) Hard/Soft template method with carbon or silica spheres, micelles, gas bubbles, surfactants as core structured precursor;[34-41] (II) The self-sacrificing template method via the Kirkendall effect;[42-44] and (III) The free template method via inside-out Ostwald ripening or others.[45, 46] However, conventional methods to prepare porous UCNCs remain difficult and suffer from lower production, suface hydrophobicity, complicated operations and difficult surface treatment.[47-54]

Thus, we devloped a novel anion-induced hydrothermal oriented-explosive method. We called it the 'explosion' method because air bubbles are created during the decomposition of organic compounds. This puts pressure on precusors to simultaneously control over the size, shape and phase of porous UCNCs with water-solubility and surface funtional groups.

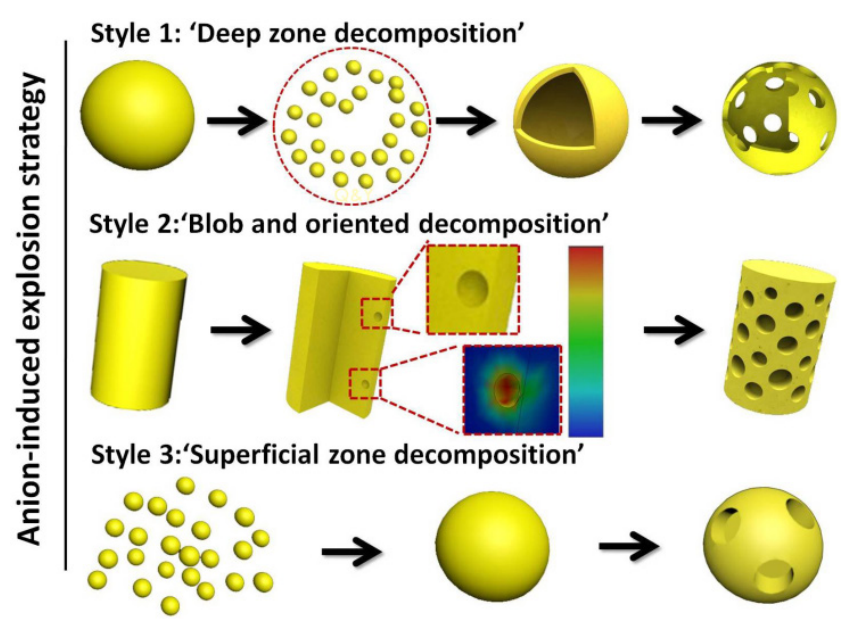

Scheme 1. Schematic illustration for the synthesis of porous upconversion nanocrystals in the hydrothermal system.

Based on this synthetic procedure, the "explosion' method (Scheme 1) was divided into three steps: (I) 'Deep zone decomposition'. This step is an intense decomposition in the centre or deep zones and results in the completed 'destruction' and 'reestablishment' for nanocrystals, which is suitable to produce hollow assemblies; (II) 'Blob and oriented decomposed techniques'. This oriented decomposition can selectively occur in certain crystal facets and crystal orientations based on the change of energy for different crystal facets, which facilitates the formation of porous rods and porous hamburger structures; and (III) 'Superfi- cial zone decomposition'. This step is a mild decomposition in superficial zones leading to superficial porous nanoparticles just like the surface of the moon. The three reaction steps are a cyclic and continuous process, which includes 'transition from rough to smooth surface', 'explosion', 'ionic erosion', 'self-assembly and self-healing' and 'further explosion'. The size, depth and morphology of cavities and hollow structures can be finely tuned by selecting the proportions, varieties and combination of 'morphology control agents' and 'explosion powders'. It has been demonstrated that the mild 'explosion powders' can prepare the porous nanoparticles, and the violent 'explosion powders' can destroy the structures of host materials partially or thoroughly with typical deep cavities or hollow assembled structures.

\section{Experimental Section}

\section{Materials}

$\mathrm{RE}_{2} \mathrm{O}_{3}$ powders (RE: $\mathrm{Lu}, \mathrm{Gd}, \mathrm{Yb}$ and Er), dodecyl dimethyl benzyl ammonium chloride (DDBAC), glycolic acid (GA), cetyltrimethyl ammonium bromide (CTAB), potassium sodium tartrate (PST) and trisodium citrate (TSC) were all analytical grade and purchased from Aladdin Reagent Co., Ltd. These lanthanide oxides were dissolved in dilute hydrochloric acid, respectively, to obtain $0.4 \mathrm{M} \mathrm{LuCl}_{3}, 0.4 \mathrm{M} \mathrm{GdCl}_{3}$, $0.4 \mathrm{M} \mathrm{YbCl}_{3}$ and $0.1 \mathrm{M} \mathrm{ErCl}_{3}$ solutions.

\section{Synthesis of $\mathrm{NaLuF}_{4}$ hollow flower-like assem- blies}

In a typical procedure for the preparation of $\mathrm{NaLuF}_{4}: 20 \% \mathrm{Yb}^{3+}, 2 \% \mathrm{Er}^{3+}$, the cationic surfactant and GA were dissolved to $10 \mathrm{ml}$ deionized water, and then add the $\mathrm{RECl}_{3}$ to form a metal-chelating mixed solution. NaF (12 mmol, $15 \mathrm{ml})$ solution was added dropwise into the solution to obtain a white complex (about 40-60 drops/min), and the detailed mole ratio is $\mathrm{Ln}: \mathrm{DDBAC}$ : GA:NaF=2:1:4-6:12. The $\mathrm{pH}$ value was an important influencing factor for the final morphologies. We adjusted the $\mathrm{pH}$ value to 4 with diluted hydrochloric acid solution. After vigorous stirring for $2 \mathrm{~h}$, the white complex was transferred into a Teflon-lined autoclave and heated at $230{ }^{\circ} \mathrm{C}$ for $12 \mathrm{~h}$. When the autoclave was naturally cooled to room temperature, the precipitate was collected by centrifugation at $8500 \mathrm{rpm}$ and washed with deionized water three times. Finally, the white products were dried at $50{ }^{\circ} \mathrm{C}$ for $24 \mathrm{~h}$.

\section{Synthesis of other porous upconversion nano- crystals}

The concrete synthesis routes of other porous nanomaterials with various morphologies are similar to $\mathrm{NaLuF}_{4}$ hollow flower-like assemblies. The main 
distinctions are the different proportions, hydrothermal time, various 'morphology control agents' and 'explosion powders'.

Synthesis of $\mathrm{NaGdF}_{4}: 20 \% \mathrm{Yb}^{3+}, 2 \% \mathrm{Er}^{3+}$ porous nanorods: Ln:DDBAC:GA:NaF =1:1:6-8:12.

Synthesis of $\mathrm{NaGdF}_{4}: 20 \% \mathrm{Yb}^{3+}, 2 \% \mathrm{Er}^{3+}$ porous short nanorods:Ln:CTAB:GA:NaF =1:1:6-8:12.

Synthesis of $\mathrm{NaLuF}_{4}: 20 \% \mathrm{Yb}^{3+}, 2 \% \mathrm{Er}^{3+}$ superficial porous nanoparticles: Ln:DDBAC:PST:NaF =2:1:1:12.

\section{Characterization}

The crystal structures, sizes, morphologies and elementary compositions were characterized by scanning electron microscopy (SEM, FEI-Sirion 200), Energy Dispersive Spectrometer (EDS), low resolution transmission electron microscopy (TEM, JEM-2010), high-resolution transmission electron microscopy (HRTEM, JEM-2100F) and selected area electron diffraction (SAED, JEM-2100F). The crystalline compositions and phases of as-prepared UCNPs were characterized by an X-ray diffractometer (XRD, D8 ADVANCE, BRUKER-AXS) using $\mathrm{Cu}$ Ka radiation at $1.5418 \mathrm{~nm}$ at a scanning rate of 10 degrees/min. The specific surface area was obtained by the Brunauer-Emmett-Teller (BET, V-Sorb 2800P) method, and the pore size distribution was calculated by the Barret-Joyner-Halenda (BJH) method. Fourier Transform Infrared Spectroscopy (FTIR) was performed on Nicolet 6700 (Thermo Fisher, America). Thermal gravity analysis (TGA) was measured with Pyris 1TGA (Perkin Elmer, America), and differential scanning calorimetry was performed with a DSC 204F1 (Netzsch, Germany). The X-ray photoelectron spectra were measured with an AXIS ULTRA DLD (Kratos). Upconversion luminescence spectra of samples were obtained on FL4000 fluorophotometer at room temperature in conjunction with a $980 \mathrm{~nm}$ diode laser. The UV-vis spectra were measured with a Varian Cary50 UV-visible spectrophotometer and equipped with a $10 \mathrm{~mm}$ quartz cell.

\section{CT imaging experiments}

An aqueous solution of $\mathrm{NaGdF}_{4}$ from $0.2-10$ $\mathrm{mg} / \mathrm{ml}$ was measured using a clinical CT (TSX-101A, Japan). The attenuation values (Hounsfield Units) were obtained with CT imaging software. Two female nude mice weighing 20-25 g were purchased from Shanghai SLAC Laboratory Animal Co. Ltd. (Shanghai, China). All animal procedures were in agreement with institutional animal use and care regulations.

\section{Results and Discussion}

$\mathrm{NaLuF}_{4}: \mathrm{Yb}^{3+}, \mathrm{Er}^{3+}$ hollow flower-like assemblies (200-250 nm) and $\mathrm{NaGdF}_{4}: \mathrm{Yb}^{3+}, \mathrm{Er}^{3+}$ porous rods (length: diameter=2.5-3) were formed in the ani- on-induced hydrothermal 'explosion' process with the coordinating functions of GA and DDBAC auxiliary additives (Fig. 1a-b), respectively. Of note, GA is a small molecular weight natural fruit acid extracted from sugarcane. It is used as a natural skin-moisturizing factor because of its excellent water solubility and biocompatibility. When the hydrothermal temperature reaches $150^{\circ} \mathrm{C}, \mathrm{GA}$ will decompose rapidly to produce gas. The cationic surfactant DDBAC has good biocompatibility, water solubility and is relatively stable.

The crystal lattice distortion would expand the lattice constant of host materials when the bigger ionic radius $\mathrm{Yb}^{3+}$ or $\mathrm{Er}^{3+}$ is doped into the substrates (see Supplementary Material Part I). The $\mathrm{N}_{2}$ adsorption-desorption isotherms of $\mathrm{NaLuF}_{4}$ and $\mathrm{NaGdF}_{4}$ nanocrystals are shown in Fig. 1c-d. The typical IV-type isotherms between 0.2 and $0.85 \mathrm{P} / \mathrm{P}_{0}$ indicate that the samples possess many pore defects and fractures on their surface. Through the analysis of hysteresis loops, we can obtain specific pore structure information. The type H4 loop with parallel branches at relative pressures between 0.85 and $1.0 \mathrm{P} / \mathrm{P}_{0}$ is caused by the hollow cavity space and 'slit hole' structure. Obviously, the hollow cavity space is produced by the corrosive $\mathrm{F}^{-}$and $\mathrm{Cl}^{-}$ions in the hydrothermal system, because they can continuously corrode substrate materials to form the layered structure of holes reminiscent of a terrace.

Through the BJH method, the obtained pore-size distribution curve (inset in Fig. 1c) indicated that the average pore defect sizes are $2.25 \mathrm{~nm}$ for $\mathrm{NaLuF}_{4}$ flower assemblies. The BET surface area and the pore volume are $8.26 \mathrm{~m}^{2} \mathrm{~g}^{-1}$ and $0.067 \mathrm{~cm}^{3} \mathrm{~g}^{-1}$, respectively. For $\mathrm{NaGdF}_{4}$ porous rods (Fig. 1d), the BET surface area, total pore volume and average pore sizes were calculated to be $8.07 \mathrm{~m}^{2} \mathrm{~g}^{-1}, 0.04 \mathrm{~cm}^{3} \mathrm{~g}^{-1}$ and $2.51 \mathrm{~nm}$. Combined utilization of thermogravimetric analysis (TGA) and differential scanning calorimetry (DSC) can evaluate the ligand content of $\beta-\mathrm{NaLuF}_{4}$ and $\beta-\mathrm{NaGdF}_{4}$ nanocrystals and gain some information about change of matter in different temperature stages. In the temperature region from 200 to $1200^{\circ} \mathrm{C}$, the weight loss is $30.1 \%$ for $\mathrm{NaLuF}_{4}$ and $31.8 \%$ for $\mathrm{NaGdF}_{4}$ (black curves of Fig. 1e and Fig. 1g) including the organic ligands and host materials decomposition.

The peaks at $1021^{\circ} \mathrm{C}$ and $1046^{\circ} \mathrm{C}$ are ascribed to the main decomposition stage of the host materials. To clearly evaluate the ligand content, we magnified the local TGA curve for $\mathrm{NaLuF}_{4}$ (Fig. 1f). There are two organic materials that decompose from 20 to 900 ${ }^{\circ} \mathrm{C}$. 'Stage I' is attributed to the GA main decomposition stage to produce formaldehyde, $\mathrm{CO}$ and $\mathrm{H}_{2} \mathrm{O}$, 'Stage II' should be the combustion of the organic groups (alkyl chain) in the cationic surfactant DDBAC, and 
'Stage III' is further decomposition of residues in the above stages. Through the analysis of DSC curves (Fig. 1e and Fig. 1g), we see that the $\beta-\mathrm{NaLuF}_{4}$ nanocrystals grow and have exothermic recrystallization at $945{ }^{\circ} \mathrm{C}$. At $1030{ }^{\circ} \mathrm{C}$, the molten state of $\beta-\mathrm{NaLuF}_{4}$ nanocrystals may be decomposed or oxidized to produce some oxidation products at this high temperature. Interestingly, versus $\beta-\mathrm{NaLuF}_{4}$, there are some reductions in $\beta-\mathrm{NaGdF}_{4}$ at the temperature of recrystallization $\left(\sim 816^{\circ} \mathrm{C}\right)$ and decomposition $(\sim 1040$ $\left.{ }^{\circ} \mathrm{C}\right)$. This phenomenon may also demonstrate that the
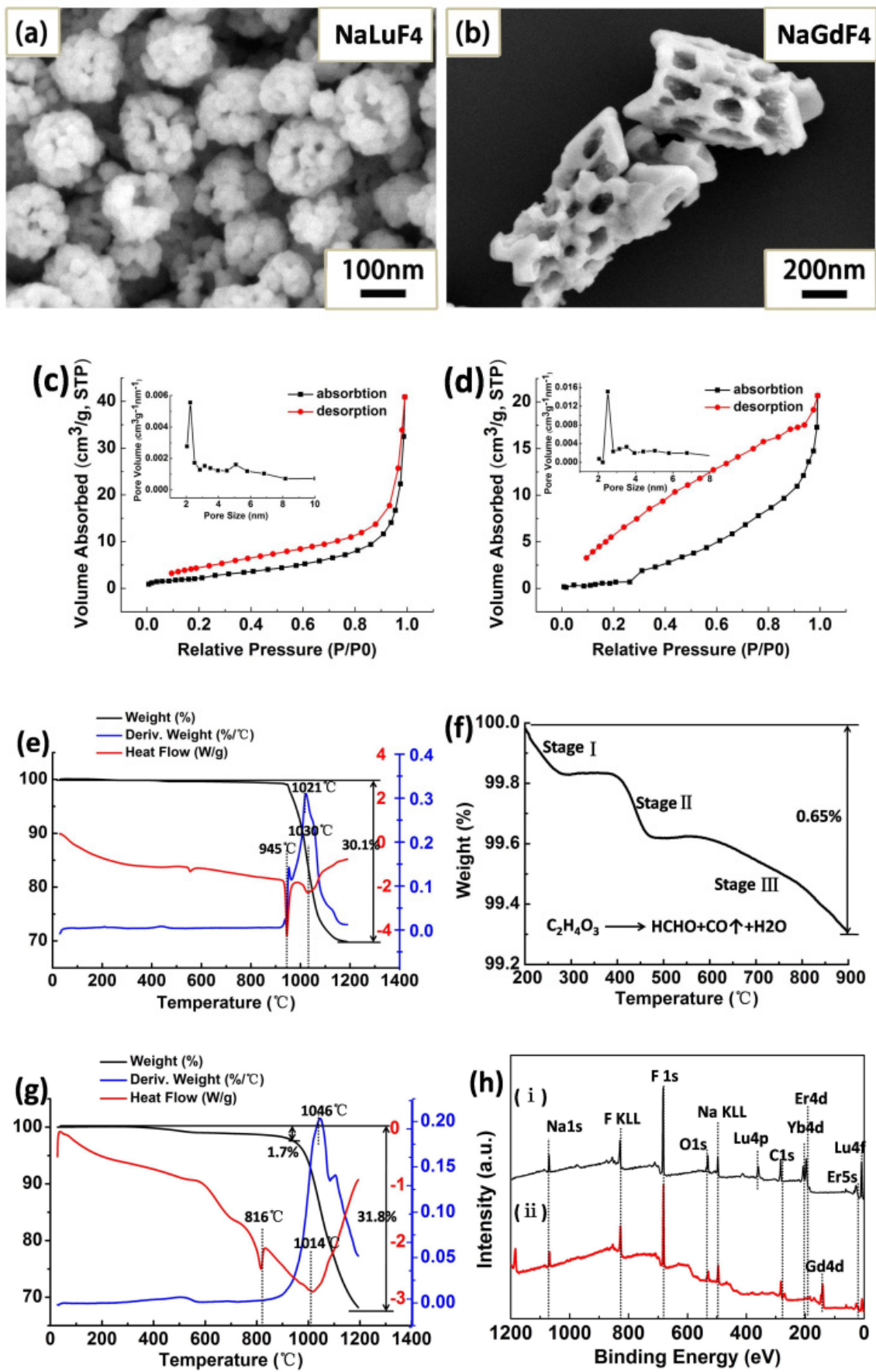

Figure 1. SEM images of $\mathrm{NaLuF}_{4}(\mathrm{a})$ and $\mathrm{NaGdF}_{4}$ (b). The $\mathrm{N}_{2}$ adsorption-desorption isotherms of NaLuF 4 (c) and $\mathrm{NaGdF}_{4}(\mathrm{~d})$. The TGA-DSC analysis of $\beta-\mathrm{NaLuF}_{4}$ hollow flower-like assemblies (e) corresponds to local magnification in the temperature range of $200-900 \circ \mathrm{C}(\mathrm{f})$ and $\beta-\mathrm{NaGdF}_{4}$ porous rods $(\mathrm{g})$. $\mathrm{XPS}$ spectra $(\mathrm{h})$ of the (i) $\beta-\mathrm{NaLuF}_{4}: \mathrm{Yb}^{3+}$, $\mathrm{Er}^{3+}$ (ii) $\beta-\mathrm{NaGdF}_{4}: \mathrm{Yb}^{3+}, \mathrm{Er}^{3+}$ display common bands ascribed to the 1s level of $\mathrm{Na}$ at $1069 \mathrm{eV}, 1 \mathrm{~s}$ level of $\mathrm{F}$ at $683 \mathrm{eV}, 1 \mathrm{~s}$ level of O $546 \mathrm{eV}, 1 \mathrm{~s}$ level of $\mathrm{C} 283 \mathrm{eV}, 4 \mathrm{~d}$ level of $\mathrm{Yb}$ at $198 \mathrm{eV}$ and the $4 \mathrm{~d}$ level of Er at $182 \mathrm{eV}$.

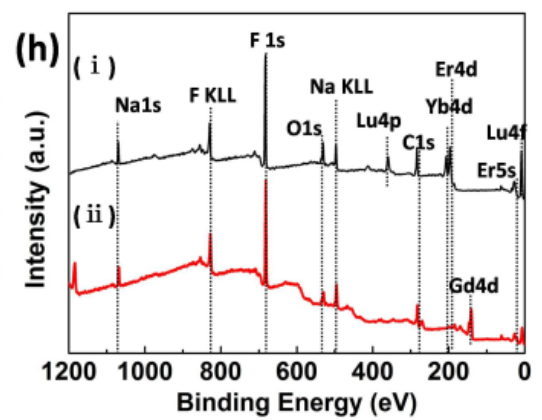

$\mathrm{NaGdF}_{4}$ host materials need less energy to be changed than $\mathrm{NaLuF}_{4}$ from the macro-perspective. X-Ray photoelectron spectroscopy (XPS) can be used to further determine successful incorporation of rare earth ions $\left(\mathrm{Yb}^{3+}\right.$ and $\left.\mathrm{Er}^{3+}\right)$ into the $\mathrm{NaLuF}_{4}$ and $\mathrm{NaGdF}_{4}$ substrates (Fig. 1h). Typically, the band energy of $\mathrm{Lu}$ $(4 \mathrm{f}, 8 \mathrm{eV})$ and $\mathrm{Gd}(4 \mathrm{~d}, 142 \mathrm{eV})$ corresponds to the $\mathrm{NaLuF}_{4}$ and $\mathrm{NaGdF}_{4}$ host materials respectively. Characteristic peaks of the carbon and oxygen components originate from the $\mathrm{C}-\mathrm{C} / \mathrm{C}-\mathrm{H}$ of DDBAC and $\mathrm{C}-\mathrm{C} /-\mathrm{OH} / \mathrm{COO}^{-}$of GA molecules.

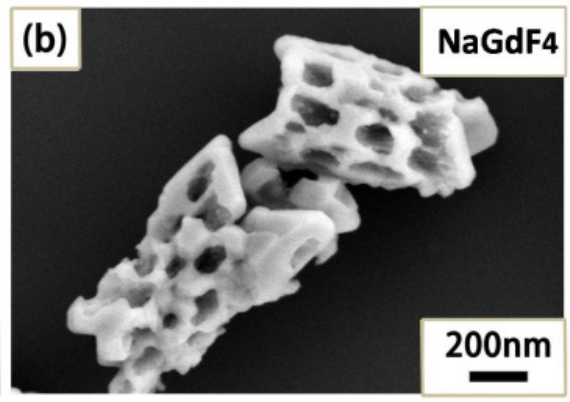


We also investigated the $\mathrm{NaLuF}_{4}$ (Fig. 2a-f) and $\mathrm{NaGdF}_{4}$ (Fig. 2g-l) nanocrystals at different stages to demonstrate the anion-induced hydrothermal oriented-explosion process (see Supplementary Material Part II), which can be divided into four typical stages: 'from rough to smooth surface', 'pressurize and explode', 'nanocrystals grow and assemble' and 'collapse of hollow/porous structure'. Because of the different characteristics of the host materials, there may be some difference in the special reaction process. Thus, we will discuss the situations for $\mathrm{NaLuF}_{4}$ and $\mathrm{NaGdF}_{4}$.

For the $\mathrm{NaLuF}_{4}$ upconversion nanocrystals, stage I: 'from rough to smooth surface'. To reduce the surface energy of the smallest nanoparticles, they aggregate to form rough nanospheres during the decomposition of the precursors. With the dissolution and recrystallization of nanoparticles, surfaces of nanospheres change from rough to smooth in the hydrothermal system at $\sim 3 \mathrm{~h}$. In this stage, numerous micro-holes will be closed to provide favorable conditions for explosion.

Stage II: 'pressurize and explode'. Because of the orientation decomposition of GA inside the smooth nanospheres, the first explosion of nanospheres will crack into smaller nanoparticles at $6 \mathrm{~h}$, which can act as a 'raw materials' for the flower-like assemblies.

Stage III: 'nanocrystals grow and assemble'. Continuous decomposition of GA molecules produce ample tiny gas bubbles as a spherical gas nucleus[38].
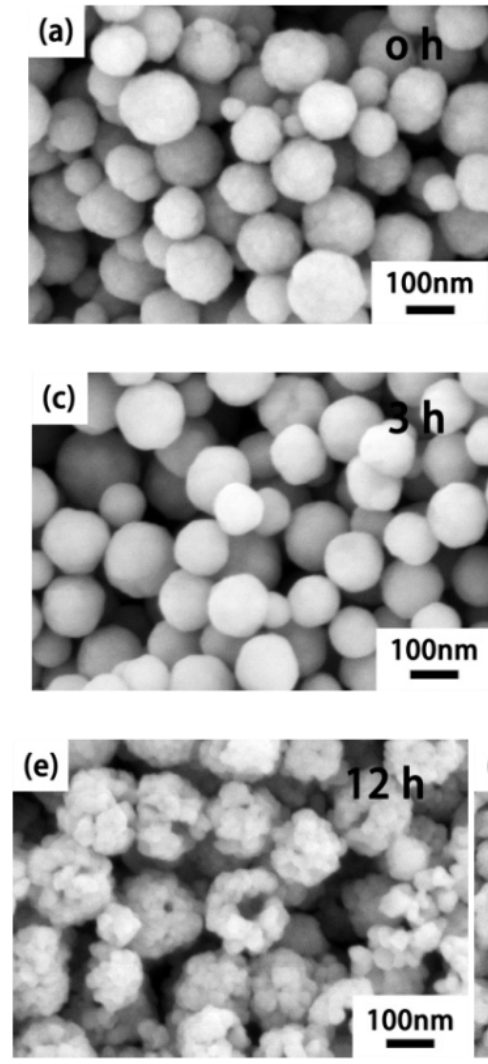
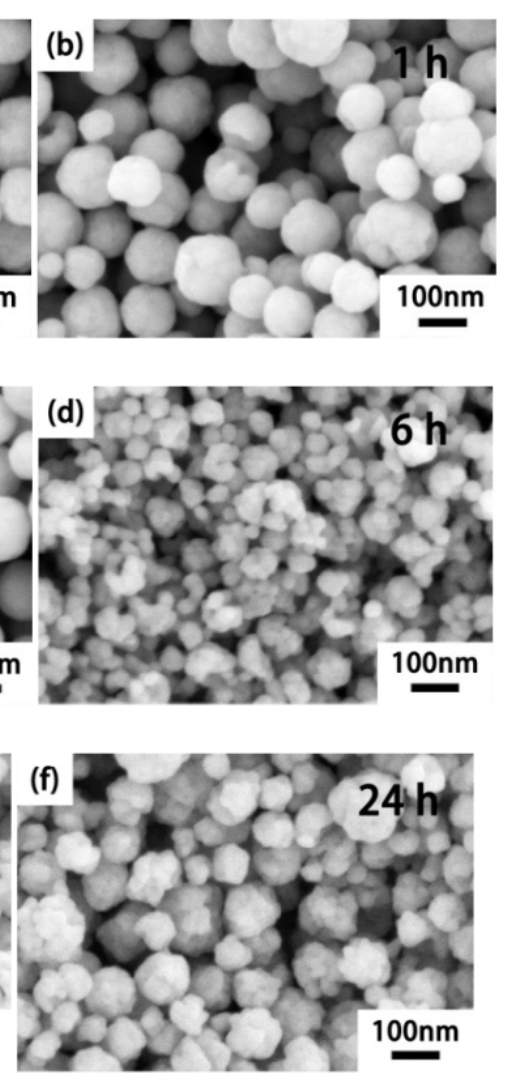

These affiliate with the smaller nanoparticles and assemble into hollow flower-like structures.

Stage IV: 'collapse of hollow structure'. With the increase in the nanoparticles affiliated on the surface of the hollow assemblies, gas channels continue to be pressurized because of the decomposition of excess residue GA. When the 'shell' cannot tolerate the tremendous pressure, the hollow and porous structure will be destroyed.

Regarding porous $\mathrm{NaGdF}_{4}$ rods, the main difference with $\mathrm{NaLuF}_{4}$ may be the phenomenon of 'secondary explosion' in the relatively short reaction time. It is noteworthy that precursors of $\mathrm{NaGdF}_{4}$ have two different morphologies: solid spherical assemblies and small claviform assemblies (Fig. 2g). The first explosion occurs on the smooth solid spherical assemblies during heating. In the first explosive stage, the reaction process occurred successively within a short time. Here it is worth mentioning that the spherical assemblies are usually the first explosive shape in the hydrothermal system because the spherical shape may have a more specific surface area than other various shapes of materials. Therefore, higher amounts of 'blasting-powder' will affiliate on the surface of the nanoparticles. In stage II, some initial nanoparticles from 'the blast fragmentation' will dissolve and close the small exhaust channel on the claviform assemblies, and the remaining species will attach to the small claviform precursors. 

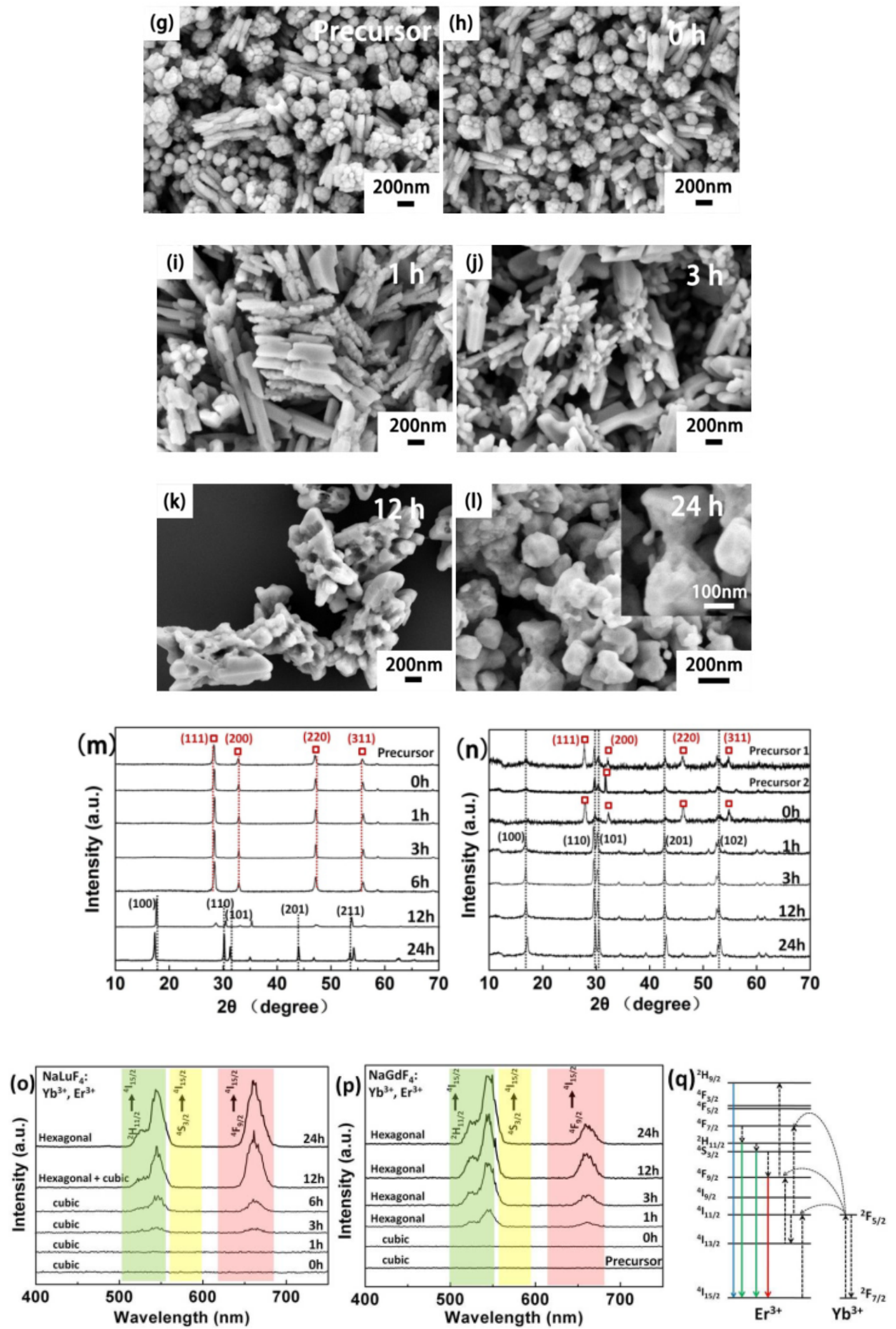

Figure 2. SEM reveals the morphology changes of the products with different reaction times (a-f) NaLuF4: $20 \% \mathrm{Yb}^{3+}, 2 \% \mathrm{Er}^{3+}$ and $(\mathrm{g}-\mathrm{l}) \mathrm{NaGdF}_{4}: 20 \% \mathrm{Yb}^{3+}, 2 \% E \mathrm{r}^{3+} \mathrm{via}^{3}$ the hydrothermal induced 'explosion' method. Phase transition in $(\mathrm{m}) \mathrm{NaLuF}_{4}: 20 \% \mathrm{Yb}^{3+}, 2 \% \mathrm{Er}^{3+}$ and $(\mathrm{n}) \mathrm{NaGdF}_{4}: 20 \% \mathrm{Yb}^{3+}, 2 \% \mathrm{Er}^{3+}$ structures along with the reaction time at $230{ }^{\circ} \mathrm{C}$. The 'precursor 1' of $\mathrm{NaGdF}_{4}$ with only GA addition and 'Precursor 2' with both DDBAC and GA. (The X-ray Diffraction peaks of cubic phase are marked with red square boxes.) Luminescence spectra (o) $\mathrm{NaLuF}_{4}: 20 \% \mathrm{Yb}^{3+}, 2 \% \mathrm{Er}^{3+}$ and (p) $\mathrm{NaGdF}_{4}: 20 \% \mathrm{Yb}^{3+}, 2 \% \mathrm{Er}^{3+}$. Energy transfer mechanisms (q) for Er $\mathrm{r}^{3+}$ and $\mathrm{Yb}^{3+}$ doped upconversion nanocrystals with $980 \mathrm{~nm}$ laser excitation. 
As the hydrothermal reaction continues, the small rods of these assemblies fuse to larger hexagonal prisms with smooth surfaces. But inside these hexagonal prisms, there are still some closed tiny cracks that act as 'gas storage vessels'. These are also places where the explosions start. With increases in gas pressure, stage III is the process of 'secondary explosion' inside the hexagonal prisms. This stage will form porous hexagonal prisms, and there are lots of defects inside these porous structures. Because of the high energy of defects, these porous structures are easily corroded to the 'terrace form' by $\mathrm{F}^{-}$and $\mathrm{Cl}^{-}$ions in the hydrothermal system.

Finally, stage IV is the 'collapse of hollow/porous structure'. Comparative analysis of the $\mathrm{NaLuF}_{4}$ and $\mathrm{NaGdF}_{4}$ preparation processes showed that the $\mathrm{NaLuF}_{4}$ need longer time and energy to complete the four stages. Morphological changes of the four stages also offer inspiration that we can prepare hollow/solid, smooth/rough spherical assemblies or porous rods by easily controlling the hydrothermal time. Fig. $2 \mathrm{~m}-\mathrm{n}$ shows there is phase transition from cubic (JCPDS 27-0725 for $\mathrm{NaLuF}_{4}$ and 27-0698 for $\mathrm{NaGdF}_{4}$ ) to hexagonal (JCPDS 27-0726 for $\mathrm{NaLuF}_{4}$ and 27-0699 $\mathrm{NaGdF}_{4}$ ) as a function of reaction time. We also found that the precursor of $\mathrm{NaLuF}_{4}$ is pure cubic phase while the precursors of $\mathrm{NaGdF}_{4}$ are cubic and hexagonal mixed phases. In the meanwhile, it is later for the appearing time of hexagonal phase $\mathrm{NaLuF}_{4}$ and cubic $\mathrm{NaYbF}_{4}$ (JCPDS 27-1426) than $\mathrm{NaGdF}_{4}$. We note that cubic $\mathrm{NaYbF}_{4}$ has similar diffraction peaks as cubic $\mathrm{NaLuF}_{4}$ except the characteristic peak at $2 \theta=58$ degree.

If the $\mathrm{Yb}^{3+}$ ions can be doped well in crystal cells of $\mathrm{NaLuF}_{4}$, the characteristic peak of cubic $\mathrm{NaYbF}_{4}$ will disappear. It is clear that the host materials with $\mathrm{Lu}^{3+}$ may need more energy to overcome energy barriers of phase transition because $\mathrm{Lu}^{3+}$ has a smaller ionic radius $(0.848 \AA)$ than $\mathrm{Gd}^{3+}(1.193 \AA)$.[55-57] This phenomenon indicates that pure hexagonal $\mathrm{NaLuF}_{4}$ upconversion nanocrystals need increased temperature or prolonged reaction time to obtain higher energy $\mathrm{Na}^{+}$or $\mathrm{RE}^{3+}$ ion redistribution. By comparing precursor 1 with 2 of $\mathrm{NaGdF}_{4}$, there is an interesting discovery that 'precursor 1 ' without DDBAC addition has more significant diffraction peaks in the cubic phase than that with DDBAC ('precursor 2').

GA and DDBAC may have some influence on phase transition, and this phenomenon also occurs in the $\mathrm{NaLuF}_{4}$ host materials. The transition from cubic phase to hexagonal phase is the process from disordered to ordered distribution of positive ions along with the enhancement of luminous efficiency (Fig. 2o-p). Energy transfer mechanisms for $\mathrm{Er}^{3+}$ - and $\mathrm{Yb}^{3+}$-doped upconversion nanocrystals have been described in Fig. 2q. It is noteworthy that there may be more surface defects and imperfect crystals for the 'precursors' and ' $0 \mathrm{~h}$ ' (Fig. 2n), which leads to the low luminescence intensity (Fig. 2o) for $\mathrm{NaGdF}_{4}$ cubic and hexagonal mixed phase. The intensity of the upconversion photoluminescence was coincided with changes in the XRD patterns.

Versus $\mathrm{NaGdF}_{4}$, we found that $\mathrm{NaLuF}_{4}$ needed longer time and energy to complete the four above-mentioned stages. We also found that GA and DDBAC have some influence on phase transition from cubic phase to hexagonal phase, which is the process from disorder to order distribution of positive ions, along with the enhancement of luminescent efficiency. In this anion-induced hydrothermal system, GA and DDBAC have different oriented-explosion effects, and the acquisition of hollow flower-like assemblies requires three preconditions (see Supplementary Material Part III).

These include: (1) explosion to get abnormal nanoparticles as the primary units, (2) gas nucleus and (3) a slightly higher concentration of $\mathrm{LuCl}_{3}$. Interestingly, we found that GA may have an inhibiting effect on the phase transition from cubic to hexagonal for $\mathrm{NaLuF}_{4}$, while the DDBAC may facilitate impact on the phase transition or weaken the inhibiting effect of GA. We suggest that the amount of small GA molecules may hinder the phase transition by disturbing the redistribution of $\mathrm{Na}^{+}, \mathrm{RE}^{3+}$ ions in the crystal cell because of the steric hindrance of hydroxide radical. This inhibition will maintain the products in the same phase as their precursors. The DDBAC may react with GA under certain conditions to inhibit the effect and promote phase transition from cubic to hexagonal. The coordinating role of the two auxiliary additives provides a new way to prepare pure cubic or hexagonal phase products by simply adjusting their proportions. Based on the above analysis and discussion, we conclude that GA has four roles in this hydrothermal anion-induced 'explosion' reaction system. They are an 'explosive powder', a morphology control agent, a source of abundant functional groups (carboxyl and hydroxyl molecules) and maintain pure cubic phase stability. The DDBAC cationic surfactant plays three roles. It is a morphology control agent, ensures limited contact among the blast fragments and weakens the GA inhibition effect from hexagonal to cubic phase.

To verify the explosive effect of GA, we adjusted the proportion of GA/ $\mathrm{Lu}^{3+}$ with (Fig. 3a-d) and without DDBAC ((Fig. 3e-h), only GA as an additive). The DDBAC is a morphology control agent and controls the dispersion and uniformity of the assemblies. The explosion becomes more violent and produces larger abnormal nanoparticles as a function of GA 
concentration (e.g. Fig. $3 g$ and Fig. 3 h). Fig. $3 g$ is a typical satellite structure with some tiny nanoparticles around the bigger nanoparticles. In Fig. 3a-d we see that the $4 \sim 6$ ratio of $\mathrm{GA} / \mathrm{Lu}^{3+}$ can obtain relatively uniform and monodisperse hollow flower-like assemblies. With increases in the GA content, the final product is $80-120 \mathrm{~nm}$ nanospheres $\left(\mathrm{GA} / \mathrm{Lu}^{3+}=8\right)$. When

Figure 3. SEM images of $\mathrm{NaLuF}_{4}$ at different proportions: (a) GA/Lu ${ }^{3+}=4$; (b) $\mathrm{GA} / \mathrm{Lu}^{3+}=6$; (c) $\mathrm{GA} / \mathrm{Lu}^{3+}=8$; (d) $\mathrm{GA} / \mathrm{Lu}^{3+}=16$ in the presence of DDBAC. Without DDBAC cationic surfactant, SEM images of the different ratios: (e) GA/Lu $\mathrm{u}^{3+}=4$, (f) GA/Lu ${ }^{3+}=6,(\mathrm{~g}) \mathrm{GA} / \mathrm{Lu}^{3+}=8$ (TEM image), (h) $\mathrm{GA} / \mathrm{Lu}^{3+}=16$. The SEM (i) and TEM (j) of $\mathrm{NaLuF}_{4}$ was prepared with only DDBAC cationic surfactant. The $\mathrm{NaLuF}_{4}$ in SEM (k) is obtained without any additives as a blank control group. The influence of reduced Lu concentration 'Lu: DDBAC: GA =1:1:6' was shown in SEM (I). Phase transition in $\mathrm{NaLuF}_{4}$ structures by adjusting the proportion of GA and $\mathrm{Lu}^{3+}$ in the presence of DDBAC $(\mathrm{m})$ and without $\operatorname{DDBAC}(\mathrm{n})$ after heating for $12 \mathrm{~h}$ at $230^{\circ} \mathrm{C}$. (Here, the $\mathrm{X}$-ray diffraction peaks corresponding to hexagonal $\mathrm{NaLuF}_{4}$ are marked with red square boxes). (o) Schematic diagram of the free energy for the controllable synthesis of $\mathrm{NaLuF}_{4}$ nanocrystals. The FTIR spectrums (P) of 1 to 4 are derived at the different ratio of $\mathrm{GA}$ to $\mathrm{Lu}^{3+}$ without DDBAC cationic surfactant, 1) $\mathrm{GA} / \mathrm{Lu}^{3+}=4,2$ ) $\mathrm{GA} / \mathrm{Lu}^{3+}=6$; 3) $\mathrm{GA} / \mathrm{Lu}^{3+}=8$; 4) GA/Lu $\mathrm{Lu}^{3+}=16$. The spectra in 5 and 6 represent $\mathrm{NaLuF}_{4}$ hollow flower-type assemblies and $\mathrm{NaGdF}_{4}$ porous rods with DDBAC and GA additives, respectively. Luminescence spectrum (q) $\mathrm{NaLuF}_{4}$ in the presence of DDBAC and $(r) \mathrm{NaLuF}_{4}$ without DDBAC.
$\mathrm{GA} / \mathrm{Lu}^{3+}=16$ there is some clustering because of the abundant functional groups on the surface. Importantly, if GA/ $\mathrm{Lu}^{3+}$ is above 8 , the products have spherical morphologies likely because GA is a morphology control agent.
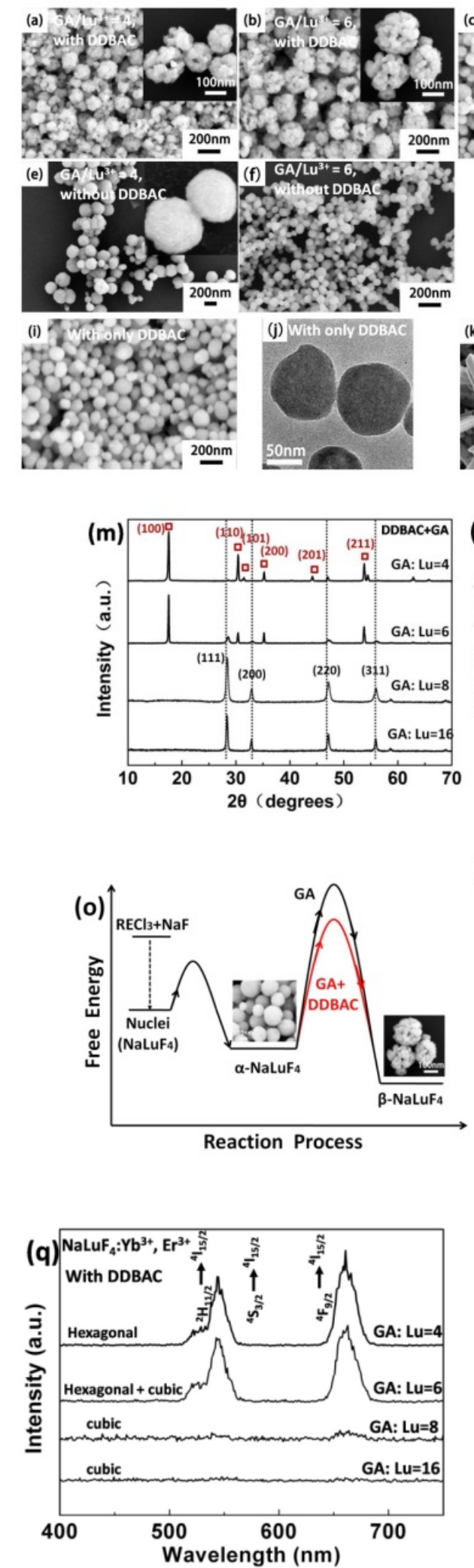
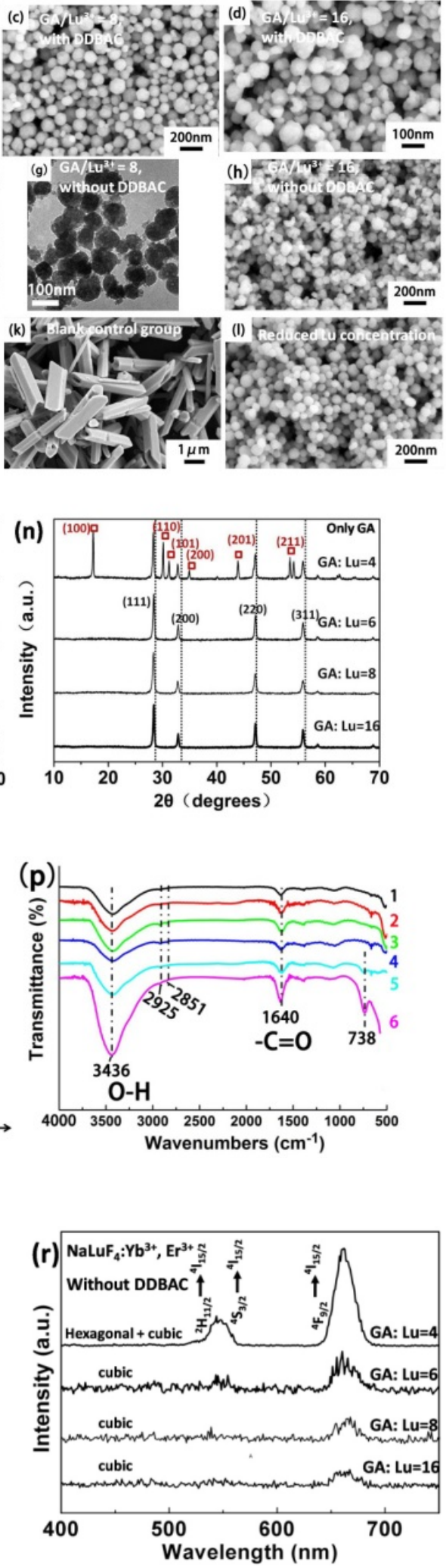
To verify this speculation, we prepared four ratios of GA/ $\mathrm{Lu}^{3+}$ (Fig. 3e-h). The nanoparticle size decreased as GA increased. Because of the severe decomposition of GA, when GA/ $\mathrm{Lu}^{3+}=16$, the amount of explosion and gas acts as a nucleus and leads to assembly of the blast fragmentation (products of explosion).

Our group has found that DDBAC is an excellent cationic surfactant in controlling size and morphology of upconversion nanomaterials in a hydrothermal system. Using only the DDBAC cationic surfactant, we obtained 80-110 nm NaLuF 4 nanoparticles with a smooth surface (Fig. $3 \mathrm{i}$ and Fig. 3j). Without the addition of any additives, we achieve smooth micro-prisms $\mathrm{NaLuF}_{4}$ 3-5 $\mu \mathrm{m}$ long with a diameter of 1-1.5 $\mu \mathrm{m}$ as the blank control group (Fig. 3k).

Fig. $3 \mathrm{~b}$ shows that the structure of the hollow flower-like assemblies is similar to '3D-Puzzles'. As we know, 'Puzzles' can be assembled through limited joining together between two adjacent 'primary units', and the adjacent units can only offer opposite planes to connect. To verify the limited contact, we decreased the $\mathrm{LuCl}_{3}$ concentration to reduce the probability of contact between adjacent initial nanoparticles because of the extension of the adjacent distance. When the proportion is adjusted to 'Lu: DDBAC: GA=1:1:6', we obtained $60-80 \mathrm{~nm}$ nanoparticles without any assembly (Fig. 31). Versus the cubic phase, the hexagonal phase is more thermodynamically stable. Nanoparticles are prone to form hexagonal micron columnar materials at higher temperature and longer time. However, products of the pure hexagonal phase are difficult to be acquired within the nanometer scale. This is because of the higher phase transition energy barrier shown in Fig. 3o. In Fig. 3m and Fig. 3n, a gradual increase in the diffraction peak intensities of the cubic phase is observed as a function of increased GA content. We can obtain pure cubic phase $\mathrm{NaLuF}_{4}$ only by adjusting the proportion of GA/Lu above 8 .

There is another discovery about the cubic to hexagonal phase transition. Upon addition of DDBAC, the hexagonal phase appears with the proportion of $\mathrm{GA}: \mathrm{Lu}=6$; pure phase can be obtained at $\mathrm{GA}: \mathrm{Lu}=4$. Without addition of DDBAC, we can only achieve cubic and hexagonal mixed phases at $\mathrm{GA}: \mathrm{Lu}=4$. To describe the process of phase transition, we made a schematic diagram of the free energy for the controllable synthesis of $\mathrm{NaLuF}_{4}$ nanocrystals (Fig. 3o). As seen in Fig. 3q-r, the luminescence intensity variation of upconversion luminescence can also coincide with changes in the XRD patterns. The surface organic groups of products were further characterized by FTIR (Fourier Transform Infrared Spectroscopy) between 500 and $4000 \mathrm{~cm}^{-1}$ (Fig. 3p). The broad absorption band near $3436 \mathrm{~cm}^{-1}$ can be as- signed to the O-H stretch of GA and the tiny peaks at 2925 and $2851 \mathrm{~cm}^{-1}$ indicate the C-H stretching vibrations from the aliphatic chain of DDBAC and GA. The peaks at $1640 \mathrm{~cm}^{-1}$ can be attributed to the $\mathrm{C}=\mathrm{O}$ stretching vibrations from the carboxylic groups. The strong peaks at $738 \mathrm{~cm}^{-1}$ are associated with the C-H bonds of the phenyl group. This means that the GA molecules and its decomposition products provide abundant carboxyl and hydroxyl groups to be further used in biological coupling and modification.

By varying the permutation and combination of $\mathrm{F} / \mathrm{Lu}$ and temperature we learned how the fluorine ions influence the product morphologies and phase transition (see Supplementary Material Part IV). Based on this insight, we next proposed a mechanism of the morphology and phase changing process of fluorine ions relative to orientation and absorption.

The effect of fluorine ions has three contributions: (a) 'Precursor stage'. Rare earth chloride $\left(\mathrm{RECl}_{3}\right), \mathrm{DDBAC}$ and GA were mixed together in aqueous solution at room temperature. Upon addition of $\mathrm{NaF}$ solution, the rare earth ions, $\mathrm{Na}$ and $\mathrm{F}$ ions reacted and formed the small precursor particles under the control of DDBAC and GA. Then the small precursor particles will aggregate together and assemble larger loose particles (about 100-250 nm) with rough surface because of the high surface energy.[58-60] The proportion of $(\mathrm{F} / \mathrm{Lu}=4,8,12)$ has no influence on the precursor morphology.

(b) 'Morphological changes induced by excessive fluorine ions'. The absorption differences between fluorine ions and each crystalline plane of the precursors may promote the epitaxial growth of nuclei along these orientations. An 'F/Lu=4' conforms as the stoichiometric ratio of $\mathrm{NaLuF}_{4}$. When the proportion of $\mathrm{F} / \mathrm{Lu}$ is over 4 , the absorption capability of excess fluorine ions on the z-axis may be weaker than on the other six crystalline planes. With increases in hydrothermal temperature, the homogeneous reaction system will be destroyed, and then fluorine ions absorbed on the $z$-axis are gradually released. Finally, the growth of the precursors along with z-axis can obtain the hexagonal columnar structure with perfect crystallinity. When $\mathrm{F} / \mathrm{Lu}=8,12$ at $230-250{ }^{\circ} \mathrm{C}$, we found that the length-diameter ratio of the columnar structure has a decreasing trend with increases in fluorine ions. As the proportion of $\mathrm{F} / \mathrm{Lu}$ increased, the (0001) plane of the hexagonal column will also absorb more fluorine ions and hindering the growth of the nuclei along with z-axis. When $\mathrm{F} / \mathrm{Lu}=4$ and the temperature exceeds $240^{\circ} \mathrm{C}$, these small nanoparticles will fuse and grow into short columnar structures.

(c) Phase transition induced by fluorine ions.[58, 59, 61-63]. Elevating the proportion of F/Lu not only changes the morphology from nanoparticles to a mi- 
cro-columnar structure, but also promotes the phase transition from cubic to hexagonal phase. This increases the luminescent efficiency of the upconversion nanomaterials. Because of the energy fluctuation during precursor preparation, there are still some tiny hexagonal products in the majority of precursors for the cubic phase. Due to selective absorption of fluorine ions on different crystal planes, these tiny hexagonal precursors optimize orientation growth. In this hydrothermal system, the optimal orientation is the (0001) direction. When the other cubic phase crystallites fuse with these tiny hexagonal crystallites, they will rotate to reach the same orientation of the slightly bigger hexagonal rods. During this process, these cubic phase crystallites will transform to the hexagonal phase and gradually grow up to be a hexagonal columnar structure.

Our previous experiments illustrated that the cationic surfactant DDBAC has better biocompatibility and water solubility versus CTAB.[64] Thus, we replaced $\mathrm{CTAB}$ with DDBAC as the morphology control agent. The 'explosion powder' is still GA.[65] Based on this 'explosion' method, we prepared porous $\mathrm{NaGdF}_{4}$ short rod-like structures (Length: 600-800 nm, Diameter: 300-400 nm, L:D=1.5-2; Fig. $4 a-b)$. This may be caused by the stronger adsorption capability for CTAB than DDBAC additives on the surface of porous $\mathrm{NaGdF}_{4}$ nanorods in the hydrothermal system. CTAB is abundant and low cost and could facilitate potential large-scale preparation methods. We can also prepare $80-100 \mathrm{~nm}$ porous $\mathrm{NaLuF}_{4}$ nanoparticles (Fig. 4c-f) with DDBAC and PST (Lu: DDBAC: PST=1:1:1). Versus the preparation of porous structures with GA, the PST may be a moderate 'explosion powder' because of the higher decomposition temperature (PST: $220^{\circ} \mathrm{C}, \mathrm{GA}: 100^{\circ} \mathrm{C}$, hydrothermal temperature: $230^{\circ} \mathrm{C}$ ). The mild explosions occur slowly on the surface of $\beta-\mathrm{NaLuF}_{4}$ nanoparticles and do not destroy the original $\beta-\mathrm{NaLuF}_{4}$ morphology and size. This suggests we can choose one kind of mild 'explosion powder' to prepare porous surface structures.

To further validate the 'deep zone decomposition', 'blob and oriented decomposition techniques' and 'superficial zone decomposition' process for the 'explosion' process, we simulated the process by the 'generalized Hooke law' (see Supplementary Material Part V) via Solidworks software. A typical 'deep zone decomposition' process is shown in Fig. 5. This step is an intense multipoint simultaneous explosion resulting in thorough 'catastrophic failure', 'destruction' and 'reestablishment' of nanomaterials. It creates hollow assemblies. The 'explosive powder' can rapidly decompose and produce ample gas in a short time.

As the number of holes increased from Fig. 5a to Fig. $5 c$, the hole color in the middle zone changes because of the stress distribution. There are distinct color changes for two situations: 'the single center hole' and 'the center hole in 20 holes model' as shown in Fig. 5d-e. This means that the real stress in each hole is reduced and effectively distributed in the whole system, even though the external load added on each hole still remains the same. This phenomenon also means that the loading limit for each hole to reach an orange color is increased because of the effective stress distribution for this 'pomegranate' model (Fig. 5f). The explosion in multipoint can occur simultaneously to completely destruct the original precursor structure. This phenomenon of reduced stress distribution can be explained via the material porosity.

Porosity has some impact on the elasticity modulus because $E_{\text {eff }}=E_{0}(1-p) /(1+2.5 p)$. Here, ' $E_{0}$ ' is elasticity modulus of materials without holes, and ' $p$ ' is the porosity $(0<p<1)$. From this equation, we can infer that the elasticity modulus value decreases with increases in porosity. Thus, the stress will decrease because of Hooke's law.

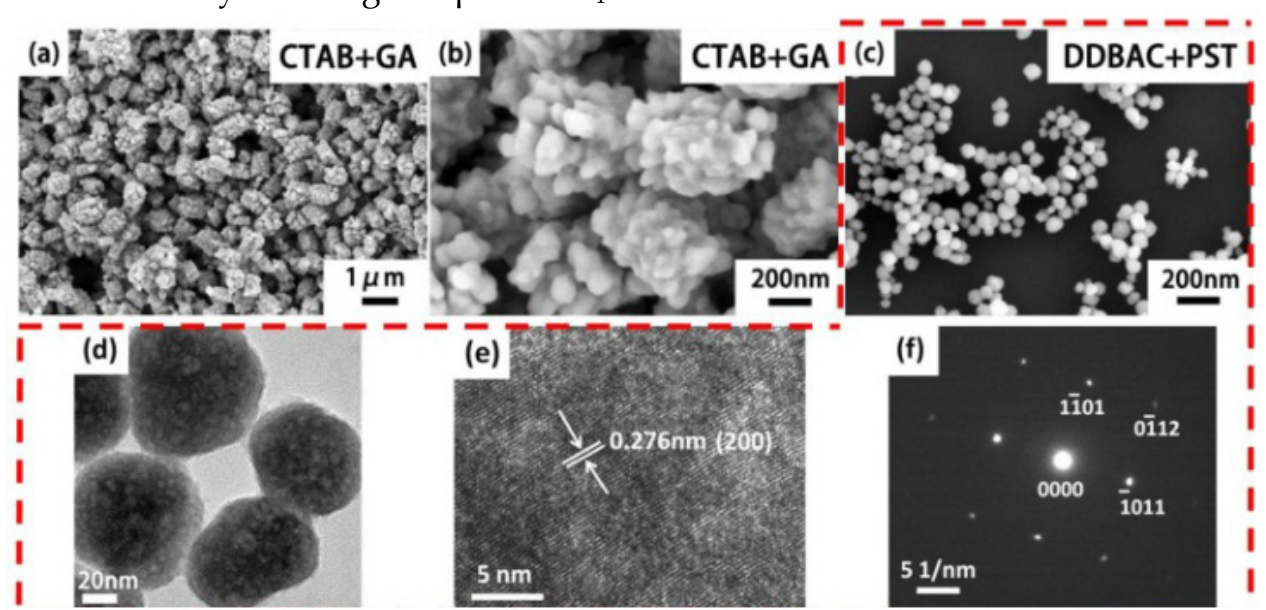

Figure 4. SEM images of porous $\beta-\mathrm{NaGdF}_{4}$ rods (a) and local magnification (b) with CTAB+GA. SEM (c), TEM (d), HRTEM (e) and SAED (f) of the 80-100 nm porous $\beta-\mathrm{NaLuF}_{4}$ nanoparticles with DDBAC+PST. 


\section{‘Pomegranate' model}

(a)

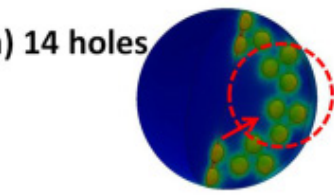

(b) 19 holes

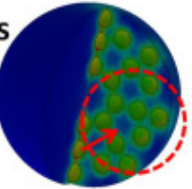

(c) 20 holes
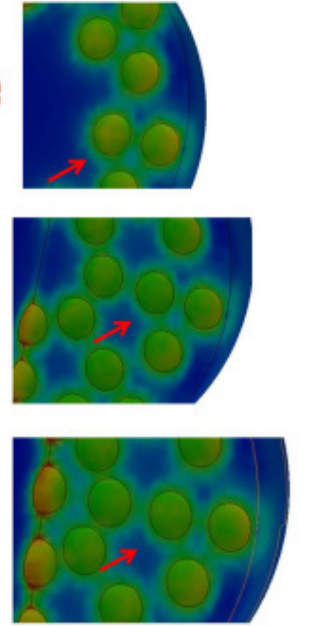

(d)



(e)

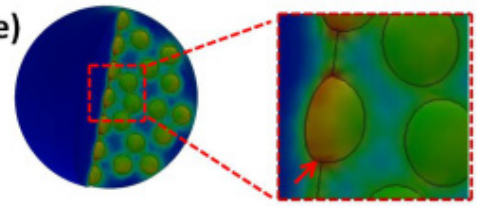

(f) 'Pomegranate'

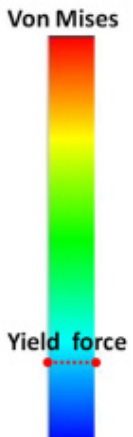

Figure 5. Simulation of 'Deep zone blast'. The stress distribution is seen for different numbers of holes including (a) 14 holes, (b) 19 holes and (c) 20 holes. The stress distribution for (d) considers the single center hole in the whole sphere and (e) a situation in which the center hole is 20 holes. This blasting style is similar to the 'pomegranate' model (f).

To demonstrate the potential feasibility of the synthesized upconversion nanocrystals for the in vitro and in vivo CT imaging, we also studied CT signal attenuation $(\mathrm{HU})$ variations along with the concentration of samples and performed experiments on the back tissue of nude mice using subcutaneous injection with water-soluble $\mathrm{NaLuF}_{4}: \mathrm{Yb}^{3+} / \mathrm{Er}^{3+}$ upconversion nanoparticles dispersed in PBS. Fig. 6a shows CT images of $\mathrm{NaLuF}_{4}$ hollow flower-like assemblies at different concentrations $(0.2-10 \mathrm{mg} / \mathrm{ml})$. The CT signal clearly increases as a function of $\mathrm{NaLuF}_{4}$ nanocrystal concentration.[66-68] The $\mathrm{NaLuF}_{4}$ nanocrystals have a well-correlated linear relationaship $\left(\mathrm{Y}=14.17 \mathrm{X}-10.8, \mathrm{R}^{2}=0.9974\right)$ as shown in Fig. 6b. For in vivo CT imaging, $200 \mu \mathrm{l}(20 \mathrm{mg} / \mathrm{ml}) \mathrm{NaLuF}_{4}: \mathrm{Yb}^{3+} / \mathrm{Er}^{3+}$ were injected into the mouse. After injection (Fig. 7), the corresponding injection sites (back normal tissue) showed an obviously increased CT signal increasing from 26 to 425 (HU). This indicates that the $\mathrm{NaLuF}_{4}: \mathrm{Yb}^{3+} / \mathrm{Er}^{3+}$ nanocrystals could act as CT contrast agents.


Figure 6. The in vitro CT images (a) of lanthanide-doped $\mathrm{NaLuF}_{4}$ hollow upconversion nanoparticles in aqueous solution. The CT signal attenuation (HU) plot (b) of $\mathrm{NaLuF}_{4}$ varies with concentration from $0.2-10 \mathrm{mg} / \mathrm{ml}$.

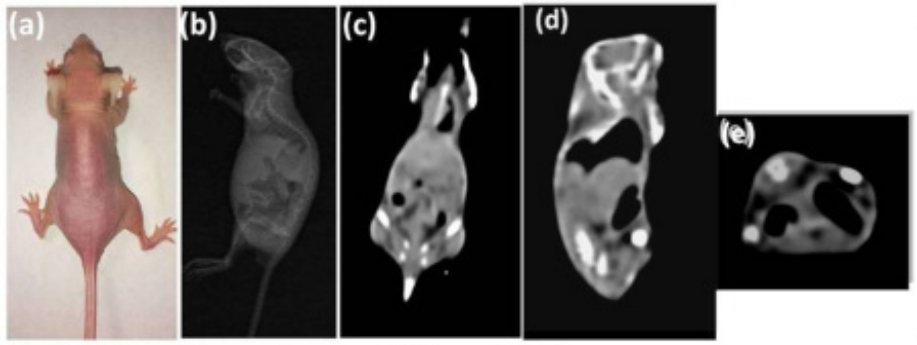

(I) Control group images of vivo nude mice

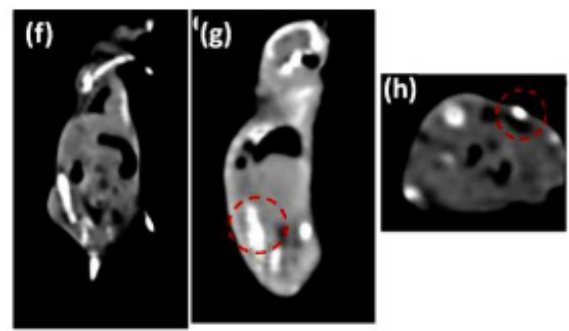

(II) CT images of vivo nude mice

Figure 7. (I) Images of control group before injection: (a) The photograph of the nude mouse; (b) X-ray image and (c)(d)(e) CT images of nude mouse model as a control. (II) $\mathrm{CT}$ images of coronal plane $(\mathrm{f})$, sagittal plane $(\mathrm{g})$ and transverse plane $(\mathrm{h})$ through subcutaneous injection with $\mathrm{NaLuF}_{4}$ upconversion nanoparticles. 


\section{Conclusions}

In summary, we report a novel anion-induced hydrothermal oriented-explosion method for synthesis of porous upconversion nanocrystals with various morphologies, sizes and phases. The 'deep zone blast', 'blob and oriented blast techniques' and 'superficial zone blast' processes were clarified by both experimental and theoretical simulation. This method is very important not only for preparing lanthanide-doped porous upconversion nanocrystals, but also for clarifying the formation process in the hydrothermal system. The synthesized porous upconversion nanocrystals were used for in vitro and in vivo CT imaging have utility as CT contrast agents.

\section{Supplementary Material}

Supplementary Material Part I-Part V. http://www.thno.org/v05p0456s1.pdf

\section{Acknowledgment}

We thank the financial support from Chinese 973 Project (2010CB933901), National Natural Science Foundation of China (No. 81225010, 81327002, 81101169 ) and 863 High-Tech project of China (2014AA020701, 2012AA0022703). Authors are also grateful for the Instrumental Analytical Center of Shanghai Jiao Tong University.

\section{Author Contributions}

The manuscript was written through contributions of all authors. All authors have given approval to the final version of the manuscript.

\section{Competing Interests}

The authors have declared that no competing interest exists.

\section{References}

1. Zijlmans H, Bonnet J, Burton J, Kardos K, Vail T, Niedbala R, et al. Detection of cell and tissue surface antigens using upconverting phosphors: a new reporter technology. Anal Biochem. 1999; 267: 30-6.

2. Wang F, Liu X. Recent advances in the chemistry of lanthanide-doped upconversion nanocrystals. Chemical Society reviews. 2009: 38: 976-89.

3. Qiu P, Zhou N, Chen H, Zhang C, Gao G, Cui D. Recent advances in lanthanide-doped upconversion nanomaterials: synthesis, nanostructures and surface modification. Nanoscale. 2013; 5: 11512-25.

4. Chatterjee DK, Rufaihah AJ, Zhang Y. Upconversion fluorescence imaging of cells and small animals using lanthanide doped nanocrystals. Biomaterials. 2008; 29: 937-43.

5. Naczynski DJ, Tan MC, Zevon M, Wall B, Kohl J, Kulesa A, et al Rare-earth-doped biological composites as in vivo shortwave infrared reporters. Nat Commun. 2013; 4: 2199-209.

6. Liu $\mathrm{Y}, \mathrm{Tu} \mathrm{D}, \mathrm{Zhu} \mathrm{H}, \mathrm{Ma} \mathrm{E}$, Chen $\mathrm{X}$. Lanthanide-doped luminescent nano-bioprobes: from fundamentals to biodetection. Nanoscale. 2013; 5: 1369-84.

7. Gnach A, Bednarkiewicz A. Lanthanide-doped up-converting nanoparticles: merits and challenges. Nano Today. 2012; 7: 532-63.

8. Mita Y, Hirama K, Ando N, Yamamoto H, Shionoya S. Luminescence processes in $\mathrm{Tm}^{3+}$ and $\mathrm{Er}^{3+}$ ion activated, $\mathrm{Yb}^{3+}$ ion sensitized infrared upconversion devices. J Appl Phys. 1993; 74: 4703-9.

9. Wang F, Han Y, Lim CS, Lu Y, Wang J, Xu J, et al. Simultaneous phase and size control of upconversion nanocrystals through lanthanide doping. Nature. 2010; 463: 1061-5.
10. Liu $\mathrm{J}$, Yao $\mathrm{O}$ Li $\mathrm{Y}$. Effects of downconversion luminescent film in dye-sensitized solar cells. Appl Phys Lett. 2006; 88: 173119.

11. Langrock C, Diamanti E, Roussev RV, Yamamoto Y, Fejer MM, Takesue H. Highly efficient single-photon detection at communication wavelengths by use of upconversion in reverse-proton-exchanged periodically poled $\mathrm{LiNbO}_{3}$ waveguides. Opt Lett. 2005; 30: 1725-7.

12. Liu Z, Dong K, Liu J, Han X, Ren J, Qu X. Anti-biofouling polymer-decorated lutetium-based nanoparticulate contrast agents for in vivo high-resolution trimodal imaging. Small. 2014;10:2429-38.

13. Zhou L, Chen Z, Dong K, Yin M, Ren J, Qu X. DNA-mediated construction of hollow upconversion nanoparticles for protein harvesting and near-infrared light triggered release. Adv Mater. 2014; 26: 2424-30.

14. Liu Z, Pu F, Huang S, Yuan Q, Ren J, Qu X. Long-circulating $\mathrm{Gd}_{2} \mathrm{O}_{3}$ : $\mathrm{Yb}^{3+}, \mathrm{Er}^{3+}$ upconversion nanoprobes as high-performance contrast agents for multi-modality imaging. Biomaterials. 2013; 34: 1712-21.

15. Wang F, Sun LD, Gu J, Wang YF, Feng W, Yang Y, et al. Selective heteroepitaxial nanocrystal growth of rare earth fluorides on sodium chloride: synthesis and density functional calculations. Angew Chem, Int Ed. 2012; 124: 8926-9.

16. Xia A, Chen M, Gao Y, Wu D, Feng W, Li F. Gd ${ }^{3+}$ complex-modified $\mathrm{NaLuF}_{4}$-based upconversion nanophosphors for trimodality imaging of NIR-to-NIR upconversion luminescence, x-ray computed tomography and magnetic resonance. Biomaterials. 2012; 33: 5394-405.

17. Wang $X$, Zhuang J, Peng $Q, L i Y$. A general strategy for nanocrystal synthesis. Nature. 2005; 437: 121-4.

18. Mai H-X, Zhang Y-W, Si R, Yan Z-G, Sun L-d, You L-P, et al. High quality sodium rare earth fluoride nanocrystals: controlled synthesis and optical properties. J Am Chem Soc. 2006; 128: 6426-36.

19. He M, Huang P, Zhang C, Hu H, Bao C, Gao G, et al. Dual phase-controlled synthesis of uniform lanthanide-doped $\mathrm{NaGdF}_{4}$ upconversion nanocrystals via an $\mathrm{OA} /$ ionic liquid two-phase dystem for in vivo dual-modality imaging. Adv Funct Mater. 2011; 21: 4470-7.

20. Gao G, Zhang C, Zhou Z, Zhang X, Ma J, Li C, et al. One-pot hydrothermal synthesis of lanthanide ions doped one-dimensional upconversion submicrocrystals and their potential application in vivo CT imaging. Nanoscale. 2013; 5: 351-62

21. Sun L-N, Peng H, Stich MIJ, Achatz D, Wolfbeis OS. pH sensor based on upconverting luminescent lanthanide nanorods. Chem Commun. 2009;: 5000-5002.

22. Wu Y, Li C, Yang D, Lin J. Rare earth $\beta-\mathrm{NaGdF}_{4}$ fluorides with multiform morphologies: hydrothermal synthesis and luminescent properties. J Colloid Interface Sci. 2011: 354: 429-36.

23. Na H, Woo K, Lim K, Jang HS. Rational morphology control of $\beta-\mathrm{NaYF}_{4}: \mathrm{Yb}, \mathrm{Er} / \mathrm{Tm}$ upconversion nanophosphors using a ligand, an additive, and lanthanide doping. Nanoscale. 2013; 5: 4242-51.

24. Xia T, Wang J, Lin N, Huo L, Zhao H, Mountrichas G. Template-free synthesis, growth mechanism and photoluminescent properties of $\mathrm{Ln}(\mathrm{OH})_{3}$ and $\mathrm{Ln}_{2} \mathrm{O}_{3}$ nanorods (Ln: lanthanide ion). J Alloys Compd. 2010; 507: 245-52.

25. Feng $\mathrm{S}, \mathrm{Xu}$ R. New materials in hydrothermal synthesis. Accounts of chemical research. 2001; 34: 239-47.

26. Li C, Yang J, Quan Z, Yang P, Kong D, Lin J. Different microstructures of $\beta-\mathrm{NaYF}_{4}$ fabricated by hydrothermal process: effects of $\mathrm{pH}$ values and fluoride sources. Chem Mater. 2007; 19: 4933-42.

27. Li C, Quan Z, Yang J, Yang P, Lin J. Highly uniform and monodisperse $\beta-\mathrm{NaYF}_{4}: \mathrm{Ln}^{3+}(\mathrm{Ln}=\mathrm{Eu}, \mathrm{Tb}, \mathrm{Yb} / \mathrm{Er}$, and $\mathrm{Yb} / \mathrm{Tm})$ hexagonal microprism crystals: hydrothermal synthesis and luminescent properties. Inorg Chem. 2007; 46: 6329-37.

28. Li C, Yang J, Yang P, Lian $\mathrm{H}$, Lin J. Hydrothermal synthesis of lanthanide fluorides $\mathrm{LnF}_{3}$ ( $\mathrm{Ln}=\mathrm{La}$ to $\mathrm{Lu}$ ) nano-/microcrystals with multiform structures and morphologies. Chem Mater. 2008; 20: 4317-26.

29. Feng S, Xu R. New materials in hydrothermal synthesis. Acc Chem Res. 2000; 34: 239-47.

30. Cao T, Yang Y, Gao Y, Zhou J, Li Z, Li F. High-quality water-soluble and surface-functionalized upconversion nanocrystals as luminescent probes for bioimaging. Biomaterials. 2011; 32: 2959-68.

31. Cao $\mathrm{T}$, Yang $\mathrm{Y}$, Sun $\mathrm{Y}, \mathrm{Wu} \mathrm{Y}$, Gao $\mathrm{Y}$, Feng $\mathrm{W}$, et al. Biodistribution of sub-10 $\mathrm{nm}$ PEG-modified radioactive/upconversion nanoparticles. Biomaterials. 2013; 34: 7127-34.

32. He M, Huang $\mathrm{P}$, Zhang $\mathrm{C}$, Chen F, Wang $\mathrm{C}$, Ma J, et al. A general strategy for the synthesis of upconversion rare earth fluoride nanocrystals via a novel OA/ionic liquid two-phase system. Chem Commun. 2011; 47: 9510-2.

33. He M, Huang $\mathrm{P}$, Zhang $\mathrm{C}$, Ma J, He R, Cui D. Phase and size controllable synthesis of hexagonal upconversion rare-earth fluoride nanocrystals through an oleic acid/ionic liquid two-phase system. Chem - Eur J. 2012; 18: 5954-69.

34. Dong L, An D, Gong M, Lu Y, Gao HL, Xu YJ, et al. PEGylated upconverting luminescent hollow nanospheres for drug delivery and in vivo imaging. Small. 2013; 9: 3235-41.

35. Park JU, Lee HJ, Cho W, Jo C, Oh M. Facile Synthetic route for thickness and composition tunable hollow metal oxide spheres from silica-templated coordination polymers. Adv Mater. 2011; 23: 3161-4.

36. Sasidharan M, Gunawardhana N, Inoue M, Yusa S-i, Yoshio M, Nakashima K. $\mathrm{La}_{2} \mathrm{O}_{3}$ hollow nanospheres for high performance lithium-ion rechargeable batteries. Chem Commun. 2012; 48: 3200-2 
37. Leidinger P, Popescu R, Gerthsen D, Feldmann C. Nanoscale $\mathrm{La}(\mathrm{OH})_{3}$ hollow spheres and fine-tuning of its outer diameter and cavity Size. Small. 2010; 6: 1886-91.

38. Wang $\mathrm{W}$, Jiang $\mathrm{X}$, Chen $\mathrm{K}$. $\mathrm{CePO}_{4}$ : $\mathrm{Tb}$, Gd hollow nanospheres as peroxidase mimic and magnetic-fluorescent imaging agent. Chem Commun. 2012; 48: 6839-41.

39. Peng Q, Dong Y, Li Y. ZnSe semiconductor hollow microspheres. Angew Chem, Int Ed. 2003; 42: 3027-30.

40. Yada M, Mihara M, Mouri S, Kuroki M, Kijima T. Rare earth (Er, Tm, Yb, Lu) oxide nanotubes templated by dodecylsulfate assemblies. Adv Mater. 2002; 14: 309-313.

41. Zhou L, Li Z, Liu Z, Yin M, Ren J, Qu X. One-step nucleotide-programmed growth of porous upconversion nanoparticles: application to cell labeling and drug delivery. Nanoscale. 2014; 6: 1445-52.

42. Yin Y, Rioux RM, Erdonmez CK, Hughes S, Somorjai GA, Alivisatos AP. Formation of hollow nanocrystals through the nanoscale kirkendall effect. Science. 2004; 304: 711-4.

43. Zhang F, Shi Y, Sun X, Zhao D, Stucky GD. Formation of hollow upconversion rare-earth fluoride nanospheres: nanoscale kirkendall effect during ion exchange. Chem Mater. 2009; 21: 5237-43.

44. Gao G, Qiu P, Qian Q, Zhou N, Wang K, Song H, et al. PEG-200-assisted hydrothermal method for the controlled-synthesis of highly dispersed hollow $\mathrm{Fe}_{3} \mathrm{O}_{4}$ nanoparticles. J Alloys Compd. 2013; 574: 340-4.

45. Zhang C, Li C, Peng C, Chai R, Huang S, Yang D, et al. Facile and controllable synthesis of monodisperse $\mathrm{CaF}_{2}$ and $\mathrm{CaF}_{2}$ : $\mathrm{Ce}^{3+} / \mathrm{Tb}^{3+}$ hollow spheres as efficient luminescent materials and smart drug carriers. Chem - Eur J. 2010; 16: 5672-80.

46. Lou XW, Wang Y, Yuan C, Lee JY, Archer LA. Template-free synthesis of $\mathrm{SnO}_{2}$ hollow nanostructures with high lithium storage capacity. Adv Mater. 2006; 18: 2325-9.

47. Qian HS, Guo HC, Ho PCL, Mahendran R, Zhang Y. Mesoporous silica coated upconversion fluorescent nanoparticles for photodynamic therapy. Small. 2009; 5: 2285-90.

48. Idris NM, Gnanasammandhan MK, Zhang J, Ho PC, Mahendran R, Zhang Y. In vivo photodynamic therapy using upconversion nanoparticles as remote-controlled nanotransducers. Nat Med. 2012; 18: 1580-5.

49. Gai S, Yang P, Li C, Wang W, Dai Y, Niu N, et al. Synthesis of magnetic, upconversion luminescent, and mesoporous core-shell structured nanocomposites as drug carriers. Adv Funct Mater. 2010; 20: 1166-72.

50. Chen Y, Chen H, Guo L, He Q, Chen F, Zhou J, et al. Hollow/rattle-type mesoporous nanostructures by a structural difference-based selective etching strategy. ACS Nano. 2009; 4: 529-39.

51. Lou XW, Archer LA, Yang Z. Hollow micro-/nanostructures: synthesis and applications. Adv Mater. 2008; 20: 3987-4019.

52. Hlaváček An, Sedlmeier A, Skládal P, Gorris HH. Electrophoretic characterization and purification of silica-coated photon-upconverting nanoparticles and their bioconjugates. ACS Appl Mater Interfaces. 2014; 6: 6930-5.
53. Zhang X, Zhang X, Wang S, Liu M, Zhang Y, Tao L, et al. Facile incorporation of aggregation-induced emission materials into mesoporous silica nanoparticles for intracellular imaging and cancer therapy. ACS Appl Mater Interfaces. 2013; 5: 1943-7.

54. Yuan C, Chen G, Li L, Damasco JA, Ning Z, Xing H, et al. Simultaneous multiple wavelength upconversion in a core-shell nanoparticle for enhanced near infrared light harvesting in a dye-sensitized solar cell. ACS Appl Mater Interfaces. 2014;6:18018-25.

55. Shannon Rt. Revised effective ionic radii and systematic studies of interatomic distances in halides and chalcogenides. Acta Crystallogr, Sect A: Cryst Phys, Diffr, Theor Gen Crystallogr. 1976; 32: 751-67.

56. Yang Y, Sun Y, Cao T, Peng J, Liu Y, Wu Y, et al. Hydrothermal synthesis of $\mathrm{NaLuF}_{4}:{ }^{153} \mathrm{Sm}, \mathrm{Yb}, \mathrm{Tm}$ nanoparticles and their application in dual-modality upconversion luminescence and SPECT bioimaging. Biomaterials. 2013; 34: 774-83.

57. Liu Q, Sun Y, Yang T, Feng W, Li C, Li F. Sub-10 nm hexagonal lanthanide-doped $\mathrm{NaLuF}_{4}$ upconversion nanocrystals for sensitive bioimaging in vivo. J Am Chem Soc. 2011; 133: 17122-5.

58. Zhuang, Liang, Sung HHY, Yang, Wu, Williams ID, et al. Controlled hydrothermal growth and upconversion emission of $\mathrm{NaLnF}_{4}(\mathrm{Ln}=\mathrm{Y}, \mathrm{Dy}-\mathrm{Yb})$. Inorg Chem. 2007; 46: 5404-10.

59. Tian Y, Hua R, Chen B, Yu N, Zhang W, Na L. Lanthanide dopant-induced phase transition and luminescent enhancement of $\mathrm{EuF}_{3}$ nanocrystals. CrystEngComm. 2012; 14: 8110.

60. Vitos L, Ruban A, Skriver HL, Kollar J. The surface energy of metals. Surf Sci. 1998; 411: 186-202.

61. Torrance J, Vazquez J, Mayerle J, Lee V. Discovery of a neutral-to-ionic phase transition in organic materials. Phys Rev Lett. 1981; 46: 253.

62. Kostorz G. Phase transformations in materials. Wiley-VCH; 2001.

63. Wang X, Zhuang J, Peng Q, Li Y. Hydrothermal synthesis of rare-earth fuoride nanocrystals. Inorg Chem. 2006; 45: 6661-5.

64. Qiu P, Zhou N, Wang Y, Zhang C, Wang Q, Sun R, et al. Tuning lanthanide ion-doped upconversion nanocrystals with different shapes via a one-pot cationic surfactant-assisted hydrothermal strategy. CrystEngComm. 2014; 16: 1859-63.

65. Zeng JH, Su J, Li ZH, Yan RX, Li YD. Synthesis and upconversion luminescence of hexagonal phase $\mathrm{NaYF}_{4}: \mathrm{Yb}_{1} \mathrm{Er}^{3+}$ phosphors of controlled size and morphology. Adv Mater. 2005; 17: 2119-23.

66. Zhu $X$, Zhou J, Chen M, Shi M, Feng W, Li F. Core-shell $\mathrm{Fe}_{3} \mathrm{O}_{4} @ \mathrm{NaLuF}_{4}: \mathrm{Yb}, \mathrm{Er} / \mathrm{Tm}$ nanostructure for MRI, CT and upconversion luminescence tri-modality imaging. Biomaterials. 2012; 33: 4618-27.

67. Yang $\mathrm{T}$, Sun $\mathrm{Y}$, Liu Q, Feng $\mathrm{W}$, Yang P, Li F. Cubic sub-20 nm NaLuF${ }_{4}$-based upconversion nanophosphors for high-contrast bioimaging in different animal species. Biomaterials. 2012; 33: 3733-42.

68. Xia A, Chen M, Gao Y, Wu D, Feng W, Li F. Gd ${ }^{3+}$ complex-modified $\mathrm{NaLuF}_{4}$-based upconversion nanophosphors for trimodality imaging of NIR-to-NIR upconversion luminescence, x-ray computed tomography and magnetic resonance. Biomaterials. 2012; 33: 5394-405. 